\title{
Recent Progress in Luminescent $\mathrm{Cu}(\mathrm{I})$ Halide Complexes: A Mini-Review
}

\author{
Abraham Mensah, Juan-Juan Shao, Jian-Ling Ni, Guang-Jun Li, Fang-Ming Wang * and \\ Li-Zhuang Chen *
}

School of Environmental and Chemical Engineering, Jiangsu University of Science and Technology, Zhenjiang, China

Copper(I) halide complexes are well sought-after materials due to their rich structural diversities and photophysical properties. Profoundly, there is a direct relationship between each structural variation and luminescence of these complexes, for a purported use. In this review, recent publications within the last 2 years about copper $(I)$ halide complexes, centering on their structural dimensionalities with derivatives of nitrogen, phosphorus, and sulfur ligands, have been considered alongside their effects on luminescence.

Keywords: copper(I) halides, luminescence, nitrogen ligands, sulfur ligands, phosphorus ligands

\section{OPEN ACCESS}

Edited by: Liming Fan,

North University of China, China

Reviewed by:

Wei Liu,

Sun Yat-sen University, China

Zhong-Min Su,

Changchun University of Science and Technology, China

Jun Wang,

Yancheng Teachers University, China

${ }^{*}$ Correspondence: Fang-Ming Wang wangfmzj@qq.com

Li-Zhuang Chen clz1977@sina.com

Specialty section:

This article was submitted to Supramolecular Chemistry, a section of the journal Frontiers in Chemistry

Received: 16 November 2021 Accepted: 30 November 2021

Published: 25 January 2022

Citation:

Mensah A, Shao J-J, Ni J-L, Li G-J, Wang F-M and Chen L-Z (2022) Recent Progress in Luminescent $\mathrm{Cu}(\mathrm{l})$ Halide Complexes: A Mini-Review.

Front. Chem. 9:816363. doi: 10.3389/fchem.2021.816363

\section{INTRODUCTION}

The unprecedented reports about the usage of copper(I) halide complexes as a material in various fields are directly linked to their diverse structures, accompanied by unique properties. Precisely, for each diverse and distinct structure portrayed, there is a mechanism that controls the luminescence, which is not cryptic. Hence, acquiring an in-depth understanding of the structural variations of these materials vis-a-vis their emissions is essentially paramount to their application (Wang et al., 2019; Al-Masri and Almejled, 2020). In copper(I) halide complexes, mono-, di-, tri-, and tetra-coordinated complexes with substantive shapes like linear, trigonal, and tetrahedral have been reported. Higher coordinated states have also been recorded, but they mostly depend on the condition for the synthesis (Chen et al., 2003; Conry, 2005).

The atomic radius of the anion, the structural nature of the ligand, and the method for synthesis are part of the factors that control the coordination of copper(I) halide complexes. For instance, when the anionic size is relatively big as found in iodide and the extent of steric hindrance within the ligand is lower, multi-coordinated complexes are accessible contrary to mononuclear structures with properties differing from the above-stated points (Díez-González et al., 2010). On the other hand, the extent to which a ligand is fabricated may also determine the kind of mechanisms like ILCT, MLCT, charge-transfer-to solvent, LMCT, LLCT, inter-configurational $\mathrm{CC}$, and $\sigma-a_{\pi}$ transitions that can control the luminescence from copper(I) halide complexes (Kutal, 1990; Benito et al., 2016).

Although numerous reviews from different authors concerning the luminescence of $\mathrm{Cu}^{\mathrm{I}}$, especially its complexes with halides, centering on the applications based on emission has been presented over the past years. For instance, in 2020, Ravaro et al. wrote about the "luminescent copper(I) complexes as promising materials for the next generation of energysaving OLED devices" where they focused on OLEDs, the properties, and mechanism of $\mathrm{Cu}^{\mathrm{I}}$ complexes as a good option for lighting types of equipment. Dinuclear N-heterocyclic carbene with $\mathrm{Cu}(\mathrm{I})$ complexes centered on the synthesis route and the structural properties have also been presented (Trose et al., 2018). Furthermore, Liu et al. (2017), Liu et al. (2018), and Hei et al. (2021) have also published many works about the above-mentioned complexes, under both reviews and research aspects mostly centering on their phosphorescence as an alternative source of light (Liu et al., 2017; Liu et al., 2018; Hei et al., 2021). 
From our former research studies on inorganic-organic hybrid luminescent materials (Wang et al., 2016; Wang et al., 2018; Guo et al., 2019; Wang et al., 2021) and in order not to overlap, a mini-review on recently published works within the last 2 years on $\mathrm{Cu}(\mathrm{I})$ halide complexes and their structural relationship to luminescence is herein presented. Detail-wise, vivid descriptions about the various complexes, grounded on dimensionalities and the relationship between the established geometries and their impact on luminescence shall be hammered on. Nevertheless, it is imperative to note that not all publications concerning copper(I) halides may be captured herein. In the subsequent sections, structural variations of $\mathrm{Cu}(\mathrm{I})$ halide complexes based on various ligands and their respective dimensions vis-a-vis their photoluminescence shall be discussed.

\section{NITROGEN-BASED LIGANDS}

The combination of nitrogen-based ligands with $\mathrm{CuI}$ is the pioneering work that brought the synthesis and applications of copper(I) halide complexes to light (Hardt and Pierre, 1973). As per the propensity of nitrogen to donate electrons for coordination, they can be grouped into mono, di, tri, or multidentate forms depending on the number of atoms or hetero state by combining with other donating element(s) in a ligand (Bruns et al., 2010).

\section{Zero-Dimensional Nitrogen-Based Copper(I) Halide Complexes}

Based on both monoclinic and orthorhombic systems, $C 2 / c$ and $\mathrm{Pbcn}$ space groups, two complexes, namely, $\mathrm{Cu}_{2} \mathrm{Br}_{2}$ (3,5-dimethylpyridine $)_{4}$ and $\mathrm{Cu}_{2} \mathrm{Br}_{2}$ (5-bromo-pyrimidine) were formed from two functionalized pyrimidine ligands and cuprous bromide salt correspondingly. Only the 0D complex, (1) (Figure 1A) with the chemical formula $\mathrm{Cu}_{2} \mathrm{Br}_{2}$ (3,5-dimethyl-pyridine) $)_{4}$ shall be discussed here leaving the $1 \mathrm{D}$ structure $\left(\mathrm{Cu}_{2} \mathrm{Br}_{2}\right.$ (5-bromopyrimidine) for the subsequent chapter. Complex 1 consists of a $\mathrm{Cu}_{2} \mathrm{Br}_{2}$ rhomboid dimer with two molecules of the ligand coordinating with each copper ion. At an excitation wavelength of $360 \mathrm{~nm}$ at room temperature, a green emission at $520 \mathrm{~nm}$, controlled by MLCT was observed (Supplementary Figure S1). Due to the occupancy of $\mathrm{CuBr}$ and ligand subshells at valence and conduction bands correspondingly, 1 exhibited a bandgap of $1.536 \mathrm{eV}$ with an IQY of $80.3 \%$ (Xu C. et al., 2020).

The combination of phenanthroline bearing different substituents, electron-withdrawing and donating groups at different positions with tpp and $\mathrm{CuI}$ yielded complexes 2-4 (Figures 1B-D) with the former ligand serving as a chelate agent. In general, the mononuclear copper metal coordinated with two nitrogen atoms within the phenanthroline, forming a five-sided figure with the phosphorus atom from the tpp at the apex. Furthermore, all the complexes had different space groups concurrently recorded as $C 2 / c, P-1$, and $P 2_{1} / n$ for 2-4. Even though the substituents could not have a lot of impact on their structural variations, however, they influenced the bandgap with the complexes bearing electron-donating groups displaying high values than those without. Besides, the MLCT process controlled the broad spectral emission in the solid-state at 605, (A) 620, and (B) $650 \mathrm{~nm}$ (C) in Supplementary Figure S2, respectively (Lv et al., 2021).

In a similar work with ${ }^{3}(\mathrm{M}+\mathrm{X})$ LCT-controlled emissions, the combination of another nitrogen- and phosphorus-based ligands, NP and CuI, produced comparable five-sided Figures, 5,6 and 7 (Figures 1E-G) with a tunable temperature-dependent luminescence ranging from 589 to $568 \mathrm{~nm}$ (Supplementary Figures S3A-C) under the influence of a methoxy group.

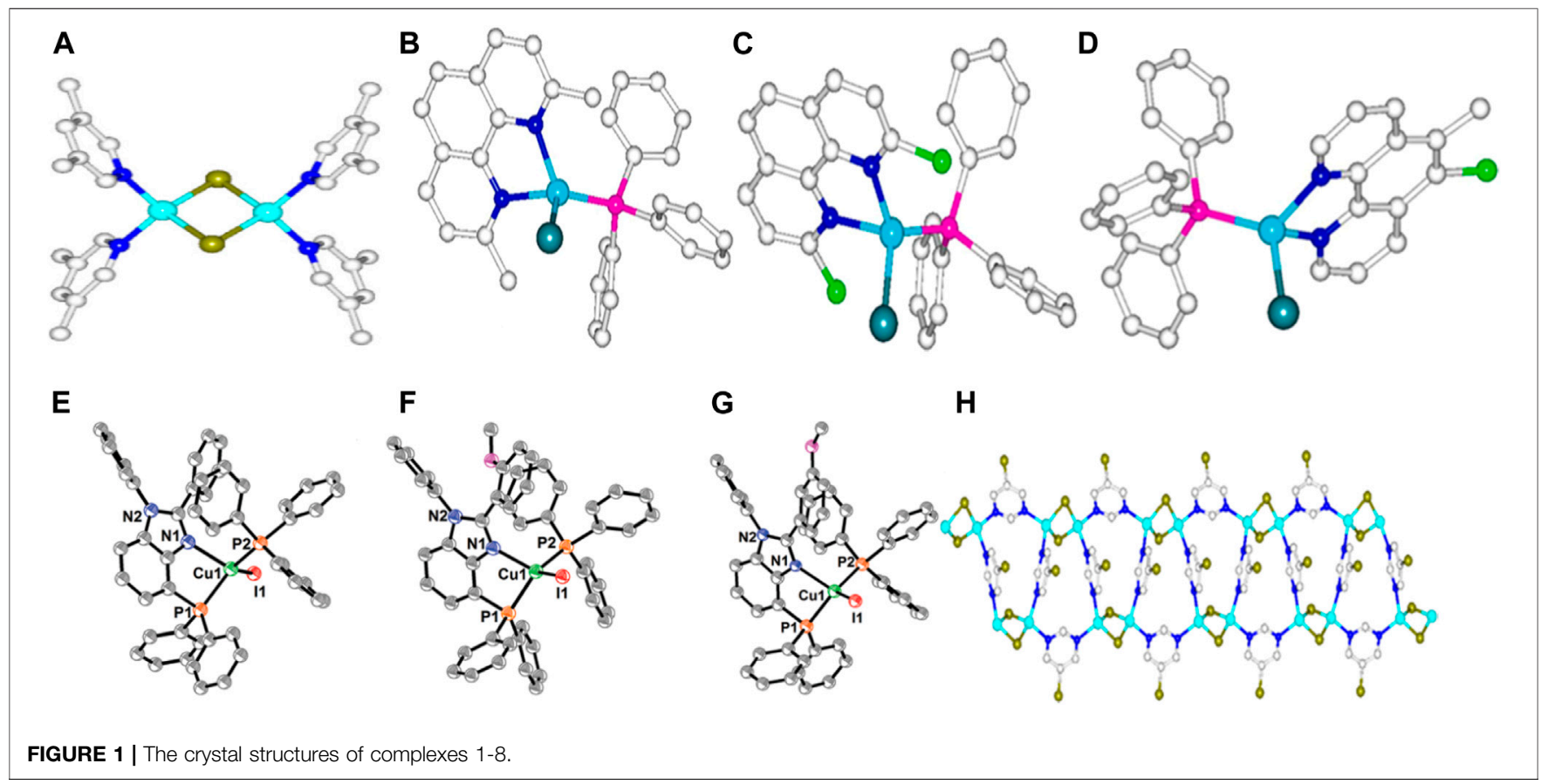


Although the complexes were collected on the same space group, nevertheless, there were variations in their internal bond length due to the positions of the methoxy substituent on the ligands. For instance, 7 with the smallest electron hindrance around the coordinating nitrogen atom had the longest $\mathrm{Cu}-\mathrm{N}$ bond distance than $\mathbf{5}$ with a directly opposite property. Also, there were fewer intermolecular interactions among the ligands due to the methoxy substituents, which prevented the formation of dimensional structures higher than OD (Zhang et al., 2021).

\section{One-Dimensional Nitrogen-Based Copper(I) Halide Complexes}

Complex 8 (Figure 1H) depicts the 1D structure synthesized using the same reagents as in $\mathbf{1}$ (Figure 1A) except that the substituents on the ligands are different. While 1 (Figure 1A) had bromide as a substituent, 8 (Figure $\mathbf{1 H}$ ) contained two methyl groups at the third and fifth positions of the ligand connecting with the dinuclear copper metal to form a $1 \mathrm{D}$ chain, directly influencing its decomposition temperature. The transitions that mired the emission of 1 (Figure 1A) above were similar to that of 8 with a potential red color at $630 \mathrm{~nm}$ (Supplementary Figure S4) (Xu C. et al., 2020).

\section{Two-Dimensional Nitrogen-Based Copper(I) Halide Complexes}

A series of multi-cluster copper(I) halide complexes, 9 and 10, namely, MCC-1 and MCCH-2 had been created from the TPPA and $\mathrm{CuI}$ in MeCN/DMF by a solvothermal synthesis at 80 and $120^{\circ} \mathrm{C}$, respectively. While the $2 \mathrm{D}$ structure 9, a noncentrosymmetric complex, was made up of a neutral cluster of $\mathrm{Cu}_{4} \mathrm{I}_{4}$ and $\mathrm{Cu}_{7} \mathrm{I}_{7}$, interconnecting to the ligand, 10, a centrosymmetric complex, consisted of ionic clusters $\mathrm{Cu}_{6} \mathrm{I}_{7}{ }^{-}$and $\mathrm{Cu}_{6} \mathrm{I}_{5}{ }^{+}$interacting with six TPPA, closing the metal-metal bond distance. Aside from the similar broadband emissions exhibited by the complexes well-organized by the ${ }^{3} \mathrm{CC}$ mechanism, the intensities of the luminescence from 9 increased while that of 10 decreased at the same conditions credited to the X/MLCT process (Supplementary Figure S5) (Yu et al., 2020).

\section{PHOSPHORUS-BASED LIGANDS}

The ubiquitous applications of phosphine-based ligands, especially with $\mathrm{Cu}(\mathrm{I})$ halides in complex formation, are their knack to stabilize structures and the possession of varying coordination trends (Kaeser et al., 2013). The number of lone pairs of electrons for coordination in the derivatives of phosphorus-based ligands is dependent on the number of donating atoms it may contain (Aguirrechu-Comeron et al., 2018).

\section{Zero-Dimensional Phosphorus-Based Ligands Copper(I) Halide Complexes}

Per the chemical structures of three nitrogen-based ligands, pyridine, quinoline, and 4-cynopyridine with phosphine
(P1-P4, Scheme S1), five different CuI complexes 11-15, (Supplementary Figure S6) were obtained in a mechanochemical synthesis. Complex 11 with P1 and pyridine had the copper metal coordinating with the iodide, nitrogen, and phosphorus from the ligands forming a tetrahedral structure on a $P 2_{1} / c$ space group with strong intermolecular interactions. Subsequently, complex 12, collected on a triclinic system, and a $P-1$ space group, containing $\mathrm{P} 1$ and quinoline, had a dinuclear coordination with the iodide, generating a planar structure. Surprisingly, 12 and $\mathbf{1 3}$ were obtained from the same reagents and procedure; however, they differed based on their $\mathrm{Cu}$. . .Cu bond distance falling at $3.0566 \AA$ and $2.8769 \AA$, correspondingly. Although 14 was made from $\mathrm{P} 4$ and pyridine, it had the same structural appearance as $\mathbf{1 2}$ except for its $\mathrm{Cu}$.... Cu distance, which was short by $0.0516 \AA$. The $\mathrm{Cu}$...Cu bond distance in $\mathbf{1 5}$ with a cubane appearance was recorded at $2.77 \AA$, being the shortest among all other complexes. The broad but varying solid-state emissions from the complexes were interdependent on the nature of the ligands with a corresponding mechanism such as ${ }^{3}(\mathrm{M}+\mathrm{X}) \mathrm{LCT}$ and ${ }^{1}(\mathrm{M}+$ X)LCT ((Supplementary Figure S6) (Egly et al., 2021).

A fused phosphorus-n combined with copper(I) halides in the $\mathrm{CH}_{2} \mathrm{Cl}_{2}$ solution yielded a set of dinuclear complexes with a general formula $\mathrm{Cu}_{2} \mathrm{X}_{2}(\mathrm{P} \cap \mathrm{N})_{3},(\mathrm{X}=\mathrm{Cl} \mathrm{Br}$ and $\mathrm{I})$. There were eight different complexes; however, only (Supplementary Figure S7) shall be centered on with their luminescence. Within the three structures, there were three substantive ligands, with two coordinating with different copper metals through their phosphorus atoms, while the third ligand joined the same metals by the nitrogen and the phosphorus groups completing a six-sided figure. Irrespective of their structural similarities, 16 was collected based on a monoclinic space group while 17 and 18, being isostructural complexes, were crystallized on a triclinic system. Furthermore, their metal-metal bond distances differed slightly even among the isostructural complexes with 16 recorded at $2.883 \AA$ whereas $\mathbf{1 7}$ and $\mathbf{1 8}$ varied by $0.0274 \AA$ with the latter being the longest. All the complexes exhibited TADF and phosphorescence emissions generated from the ${ }^{3} \mathrm{M}$ (XLCT) process, with 17 having the potential to serve as an OLED material due to its small activation energy gap at a wide temperature range (Supplementary Figure S7A) (Hofbeck et al., 2021).

\section{One-Dimensional Phosphorus-Based Copper(I) Halide Complexes}

The 1D structure 19 (Figure 2I) resulted from the strong interaction between the polymer core and the bulky hemilabile ligand $\mathrm{PymPPh}_{2}$. From the molecular formula $\left[\mathrm{Cu}_{2} \mathrm{I}_{2} \mathrm{PymPP}_{2}\right] \mathrm{n}$, the complex consists of a repetition of a double-stranded $\mathrm{CuI}$ inner core coordinating with the two different atoms within the tridentate ligand, forming a sixsided figure with the third donating atom left unattached. These extensions reduced the $\mathrm{Cu}$... Cu distances paving way for clustercentered and MLTC-induced emissions (Supplementary Figure S8A) (Davydova et al., 2020).

Artem'er and co-workers reported about three rare but similar $1 \mathrm{D}$ copper(I)-coordinating polymers with a $\mathrm{Cu}_{4} \mathrm{I}_{4}$ stair-step core 


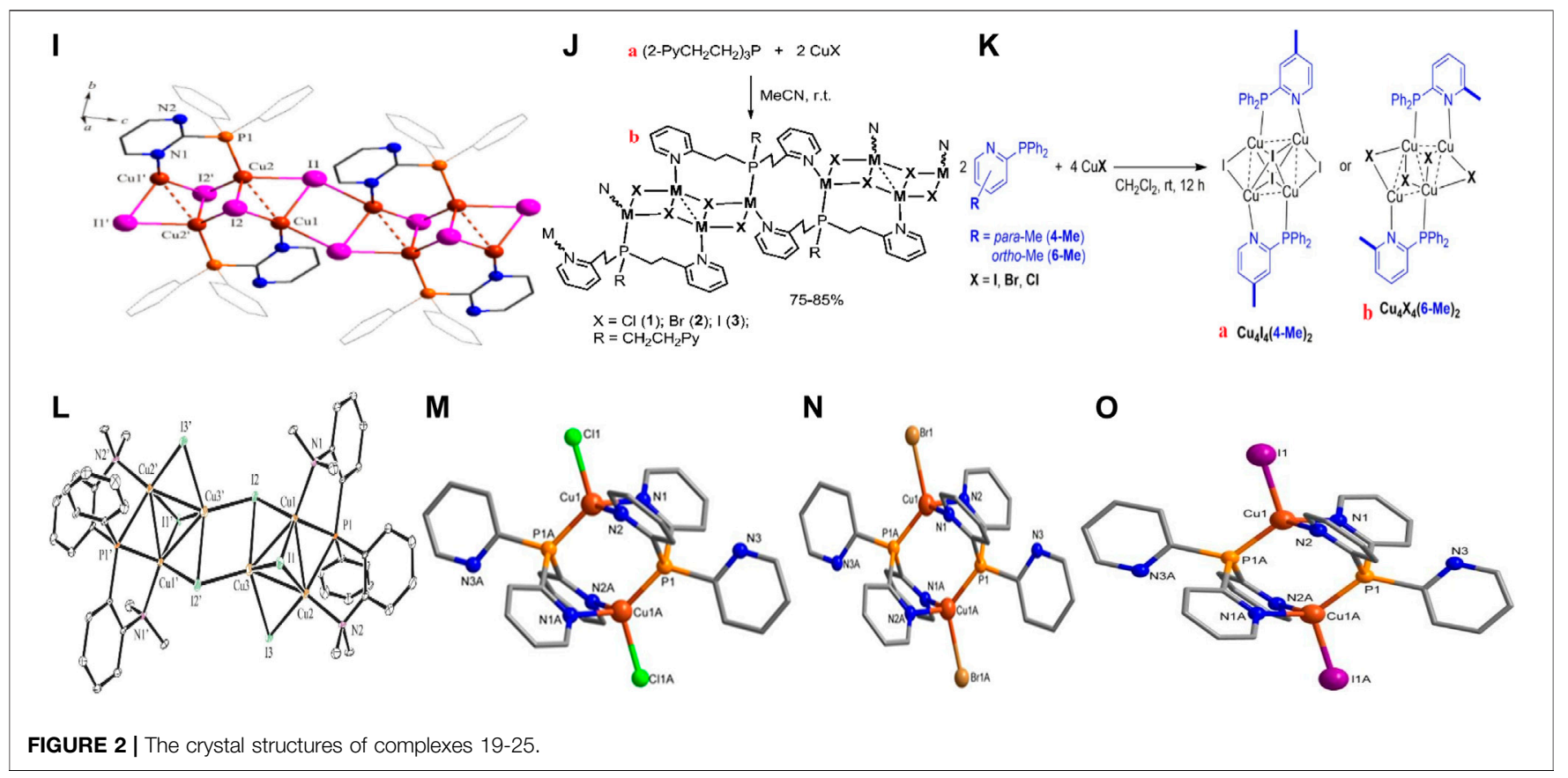

and luminescence controlled by the nature of the halogen coordinating with the metal, using the synthesis pathway in 20a (Figure 2J). A critical look at 20b Figure 2J, an isostructural complex, to the remaining two had a copper from the inner core chains joined by a phosphorus atom at one end while a nitrogen group connected the other copper metal from another section of the $\mathrm{Cu}_{4} \mathrm{I}_{4}$ structure. The complexes gave broad emissions with clear separate colors through transition within ${ }^{3}(\mathrm{M}+\mathrm{X}) \mathrm{LCT}$ states (Supplementary Figure S9A) (Artem'ev et al., 2020).

Additionally, Boden et al. also fabricated a 2(diphenylphosphino)pyridine ligand by placing a methyl group at either the para (4-Me) and ortho (6-Me) positions to the nitrogen atom to serve as a bridging ligand in $\mathrm{Cu}_{4} \mathrm{X}_{4}(\mathrm{X}$ $=\mathrm{I}, \mathrm{Cl}$ or $\mathrm{Br})$ complexes. All the complexes, $\mathrm{Cu}_{4} \mathrm{I}_{4}(4-\mathrm{Me})_{2}$, $\mathrm{Cu}_{4} \mathrm{I}_{4}(6-\mathrm{Me})_{2}, \mathrm{Cu}_{4} \mathrm{Br}_{4}(6-\mathrm{Me})_{2}$, and $\mathrm{Cu}_{4} \mathrm{Cl}_{4}(6-\mathrm{Me})_{2}$ structured in the form of either 21 a or b (Figure $2 \mathbf{K}$ ), bearing similar crystal systems and spaces groups, had their $\mathrm{CuX}$ core between two ligands connected via the nitrogen and the phosphorus atoms. Notwithstanding, the structure of $\mathrm{Cu}_{4} \mathrm{I}_{4}(6-\mathrm{Me})_{2}$ had a $\mathrm{C}_{\mathrm{i}}$ symmetry due to the location of the complex in an inversion center while $\mathrm{Cu}_{4} \mathrm{I}_{4}(4-\mathrm{Me})_{2}$ had its close to the $\mathrm{C}_{\mathrm{i}}$ symmetry, bearing a $\mathrm{Cu}$...Cu bond distance shorter than the former complex. Investigating the mechanism behind the thermochromic emission from the complexes (Supplementary Figure S10), the team concluded that the dual phosphorescence occurred due to the strong coordination pattern influencing ${ }^{3} \mathrm{M} / \mathrm{XLCT}$ and $\mathrm{CC}$ transitions (Boden et al., 2021).

\section{Two-Dimensional Phosphorus-Based Copper(I) Halide Complexes}

Figure $2 \mathrm{~L}$ consists of a complex (22) with a hexagonal CuI core obtained using a tridentate ligand consisting of phosphorus and nitrogen combined with copper(I) halides in $\mathrm{MeCN}$, collected on a triclinic system with a $P 2$ space group. To the $\mathrm{Cu}_{6} \mathrm{I}_{6}$ framework, four of the copper metals were engulfed in a tetrahedral structure from connections between two iodides, nitrogen, and a phosphorus atom from the ligand. Due to the varying atoms, a strong intermolecular interaction made from $\mathrm{CH} . \ldots \pi$ and the phenyl groups collectively held the strong $2 \mathrm{D}$ structure. This rigid framework due to the diverse coordination within the complex enhanced its white-light emission in the solid-state at room temperature as well as the blue, white through to yellow-colored luminescence at $297 \mathrm{~K}$, controlled by MLCT and XLCT mechanisms (Supplementary Figure S11A) (Xu K. et al., 2020).

\section{Three-Dimensional Phosphorus-Based Copper(I) Halide Complexes}

Complexes 23-25 (Figures 2M, M and $\mathrm{O}$ ) consist of three sets of $3 \mathrm{D}$ structures obtained through a mechanochemical synthesis using $p y_{3} p$ and $\mathrm{CuX}$ salts $(\mathrm{X}=\mathrm{Cl}, \mathrm{Br}$, and $\mathrm{I})$. The three complexes were isostructural in which the copper metal had distorted the tetrahedral shape by coordinating with two nitrogen atoms, phosphorus, and the respective halides. Albeit the weak intermolecular interactions within the complexes, they were undoubtedly the holding force within the 3D framework around an extended $\mathrm{Cu} . . \mathrm{Cu}$ bond distances. Two luminescence phenomena, TADF and phosphorescence correspondingly from ${ }^{1} \mathrm{M}+\mathrm{X}(\mathrm{LCT})$ and ${ }^{3} \mathrm{M}+\mathrm{X}(\mathrm{LCT})$ excited states displayed by the complexes were reconfirmed using DFT and TDFT approaches. (Baranov et al., 2020).

Two varying $\mathrm{CuI}$ complexes $\mathrm{Cu}_{3} \mathrm{I}_{3} \mathrm{~S}$ and $\mathrm{Cu}_{4} \mathrm{I}_{4}$ denoted as $\mathbf{2 6}$ and 27 in Supplementary Figure $\mathbf{S 1 3}$ were joined together 
by a multidentate ligand TPSA to form a 3D structure $\mathbf{2 8}$ (Supplementary Figure S13), held in shape by strong hydrogen bonds. The linkage between the adjusted coordination conforms from the ligand, the $\mathrm{Cu}_{3} \mathrm{I}_{3} \mathrm{~S}$ cluster, and the $\mathrm{Cu}_{4} \mathrm{I}_{4}$ core with a cubane-like ring resulted in a diverse rigid structure. Again, the proximity of metals to each other in the $\mathrm{Cu}_{3} \mathrm{I}_{3} \mathrm{Se}$ cluster resulted in a strong cuprous interaction than observed in the $\mathrm{Cu}_{4} \mathrm{I}_{4}$ ring. Hence, in the solid-state and at room temperature, the complex gave a red emission as a result of the metal-metal interaction in the $\mathrm{Cu}_{3} \mathrm{I}_{3} \mathrm{~S}$ and XLCT from the $\mathrm{Cu}_{4} \mathrm{I}_{4}$ (Supplementary Figure S13A) (Zhao et al., 2021).

\section{SULFUR-BASED LIGANDS}

Aside from nitrogen and phosphorus, the ligands that dominate in terms of coordination with copper(I) halides are the sulfurbased type owing to their ability to mix with other ligands serving as either an auxiliary, with the halogen as a bridge (Supplementary Figure 14A), or as a link joining the $\mathrm{CuX}$ (X $=$ halogen) core (Supplementary Figure 14B). On the other hand, the copper(I) in the midst of derivatives of sulfur ligands may also serve as a bridge to a halide to create diverse structures (Supplementary Figure 14C) (Tsuge et al., 2016).

\section{One-Dimensional Sulfur-Based Copper(I) Halide Complexes}

Complex 29 in Supplementary Figure S15 consists H6ma and $\mathrm{H}_{2} d t d n$, two mecaptonicotinic ligands and copper(I) halide in a 1D (29) and two 2D copper(I) halide-coordinating polymers (Supplementary Figure S16) from Scheme S2. The disorderliness within the ligand was the main reason for the extended $\mathrm{Cu}$. . Cu bond length, denying a CC-based emission but rather XMCTassisted luminescence at $620 \mathrm{~nm}$ in Supplementary Figure S15A (Hassanein et al., 2020).

\section{Two-Dimensional Sulfur-Based Complexes With Copper(I) Halides}

The 2D structures obtained through Scheme S2 above are displayed in Supplementary Figure S16 below as $\mathbf{3 0}$ and $\mathbf{3 1}$ with their respective emission spectra, (A,B) Supplementary Figure S16A,B. At harsh conditions, both ligands (H6ma and $\mathrm{H}_{2} d t d n$ ) with the metal salt yielded complex $\mathbf{3 0}$ crystallizing on a monoclinic system with a $\mathrm{P} 2{ }_{1} / \mathrm{c}$ space group without a halogen anion in the structure. However, when the conditions were changed, the same reagents produced 31, indicating the presence of the halide in the structure through the $\mathrm{P} 2_{1} / \mathrm{c}$ space group. The exclusion of the halide ion from complex $\mathbf{3 0}$ could not account for a halogen-assisted emission but rather a direct MLCT, with a reverse mechanism in $\mathbf{3 1}$, whereas the $2 \mathrm{D}$ structure of $\mathbf{3 0}$ was generated from the coordination between the zig-zag-shaped sulfur atoms and the copper metal; a $1 \mathrm{D}$ core of $\mathrm{Cu}_{2} \mathrm{I}_{2}$ linkage with the ligands produced the 2D appearance of $\mathbf{3 1}$ (Hassanein et al., 2020).
Dimensional coordinating polymers, with 2D (32 in Supplementary Figure S17) and three 3D structures (Supplementary Figure S18), were presented by Liang et al. with structural variations emerging from either the type of the halide or the metal-to-ligand ratio. The complexes were made from hpzt and $\mathrm{CuX}(\mathrm{X}=\mathrm{I}, \mathrm{Br}$, and $\mathrm{Cl})$ with a $1: 3$ ratio of the ligand to $\mathrm{CuI}$ yielding 32 consisting of two protonated ligands, connected by $\mathrm{Cu}^{+}$and $\mathrm{I}^{-}$in a distorted tetrahedral structure. The $2 \mathrm{D}$ structure was generated out of the interaction between $\mathrm{Cu}_{6} \mathrm{~S}_{6}$ and $\mathrm{Cu}_{4} \mathrm{~S}_{3} \mathrm{I}$ units, creating short $\mathrm{Cu}$...Cu bond distances, capable of influencing CC-assisted emissions; however, the complex was non-emissive probably due to how the molecules arranged themselves in the stacking modules (Liang et al., 2020).

\section{Three-Dimensional Sulfur-Based Copper(I) Halide Complexes}

Complexes 33-35 (Supplementary Figure S18) are the 3D structures obtained from the same synthesis procedure used for the synthesis of $\mathbf{3 2}$. From the structures, $\mathbf{3 3}$ crystallized on a monoclinic system and $I 2 / \mathrm{m}$ space group with the $3 \mathrm{D}$ figure created around two main interaction building blocks; 1) $\mathrm{CuN}_{2} \mathrm{SCl}$ and $\mathrm{Cu}_{4} \mathrm{~S}_{4}$ with a tetrahedral outlook and 2) hexagonal $\mathrm{Cu}_{6} \mathrm{~S}_{6}$ structures, which only showed temperature-regulated emission through ${ }^{3} \mathrm{CC}$ (Supplementary Figure S18). The next crystal 34, with a monoclinic but $P 2 / n$ space group, had its $3 \mathrm{D}$ outlook made via the connections between a copper metal with a tetrahedral shape formed from the coordination between two ligands and three chloride ions, with $\mathrm{Cu}_{4} \mathrm{~S}_{4}$ and a chloride ion serving as a bridge. On the other hand, 35, an isostructural to $\left[\mathrm{Cu}_{4}(\mathrm{pzt})_{3} \mathrm{I}\right]$ $\mathrm{n}$, had an interaction between $\mathrm{Cu}_{6} \mathrm{~S}_{6}$ and $\mathrm{Cu}_{2} \mathrm{Br}_{2}$ forming the 3D network (Liang et al., 2020).

\section{CONCLUSION}

In conclusion, when copper(I) halide complex material is structurally stable, the probability of exhibiting combined properties such as solubility in solutions, thermal permanency, and efficient luminescence is highly attainable for its usage. Dimensional complexes from copper(I) halide are mostly stable due to the extended bonds created among the coordinating atoms, which may enhance their emissions. Among other conditions, two factors that may play a role during the build-up to the dimensional copper(I) halide complex are hydrogen bonds and intra-ligand interactions. Comparatively, the higher the dimensionality, the more stable the structure may be due to numerous patterns of interconnecting bonds. Although most dimensionless copper(I) halides may show emissions through MLCT, CC, LMCT, LL, and XLCT, mechanisms are just like the dimensional type; however, their differences in terms of application lie within their stabilities. 


\section{AUTHOR CONTRIBUTIONS}

AM analyzed the references and drafted the manuscript. J-JS, J-LN, and G-JL helped to collect the references. F-MW conceived the idea and finalized the manuscript. L-ZC obtained the funding. All authors read and approved the final manuscript.

\section{FUNDING}

This work was financially supported by the National Natural Science Foundation of China (Grant No. 21671084).

\section{REFERENCES}

Aguirrechu-Comerón, A., Hernández-Molina, R., and González-Platas, J. (2018). Structure of Two New Compounds of Copper(I) Iodide with N-Donor and P-Donor Ligands. J. Struct. Chem. 59 (4), 943-948. doi:10.1134/ S0022476618040285

Al-Masri, H. T., and Almejled, A. A. (2020). Synthesis, X-ray Structures, and Photoluminescence of the Octahedral Cu4 I4 Cluster with Bulky Bidentate Bis(phosphanyl)amine Ligand. Z. Anorg. Allg. Chem. 646 (7), 354-358. doi:10.1002/zaac.202000058

Artem'ev, A. V., Baranov, A. Y., Rakhmanova, M. I., Malysheva, S. F., and Samsonenko, D. G. (2020). Copper(i) Halide Polymers Derived from Tris[2(pyridin-2-Yl)ethyl]phosphine: Halogen-Tunable Colorful Luminescence Spanning from Deep Blue to green. New J. Chem. 44 (17), 6916-6922. doi:10.1039/D0NJ00894J

Baranov, A. Y., Berezin, A. S., Samsonenko, D. G., Mazur, A. S., Tolstoy, P. M., Plyusnin, V. F., et al. (2020). New Cu(i) Halide Complexes Showing TADF Combined with Room Temperature Phosphorescence: the Balance Tuned by Halogens. Dalton Trans. 49 (10), 3155-3163. doi:10.1039/ d0dt00192a

Benito, Q., Maurin, I., Poggi, M., Martineau-Corcos, C., Gacoin, T., Boilot, J.-P., et al. (2016). Impact of Crystalline Packing on the Mechanochromic Luminescence Properties of Copper Based Compounds: towards Functional Coatings. J. Mater. Chem. C 4 (47), 11231-11237. doi:10.1039/ c6tc04262g

Boden, P., Di Martino-Fumo, P., Busch, J. M., Rehak, F. R., Steiger, S., Fuhr, O., et al. (2021). Investigation of Luminescent Triplet States in Tetranuclear Cu I Complexes: Thermochromism and Structural Characterization. Chem. Eur. J. 27 (17), 5439-5452. doi:10.1002/chem.202004539

Bruns, H., Patil, M., Carreras, J., Vázquez, A., Thiel, W., Goddard, R., et al. (2010). Synthesis and Coordination Properties of Nitrogen(I)-Based Ligands. Angew. Chem. Int. Edition 49 (21), 3680-3683. doi:10.1002/ anie. 200906168

Chen, L. X., Shaw, G. B., Novozhilova, I., Liu, T., Jennings, G., Attenkofer, K., et al. (2003). MLCT State Structure and Dynamics of a Copper(I) Diimine Complex Characterized by Pump-Probe X-ray and Laser Spectroscopies and DFT Calculations. J. Am. Chem. Soc. 125 (23), 7022-7034. doi:10.1021/ ja0294663

Conry, R. R. (2005). Copper: Inorganic \& Coordination Chemistry Based in Part on the Article Copper: Inorganic \& Coordination Chemistry by Rebecca R. Conry \& Kenneth D. Karlin Which Appeared in the Encyclopedia of Inorganic Chemistry, First Edition. Encyc. Inorg. Chem., 940-958. doi:10.1002/ 0470862106.ia052

Davydova, M. P., Rakhmanova, M. I., Bagryanskaya, I. Y., Brylev, K. A., and Artem'ev, A. V. (2020). A 1D Coordination Polymer Based on CuI and 2(Diphenylphosphino)Pyrimidine: Synthesis, Structure and Luminescent Properties. J. Struct. Chem. 61 (6), 894-898. doi:10.1134/ S0022476620060086

Díez-González, S., Escudero-Adán, E. C., Benet-Buchholz, J., Stevens, E. D., Slawin, A. M. Z., Nolan, S. P., et al. (2010). [(NHC)CuX] Complexes: Synthesis, Characterization and Catalytic Activities in Reduction Reactions and Click

\section{ACKNOWLEDGMENTS}

We wish to express our profound gratitude to the professors and students that contributed to the success of this work.

\section{SUPPLEMENTARY MATERIAL}

The Supplementary Material for this article can be found online at: https://www.frontiersin.org/articles/10.3389/fchem.2021.816363/ full\#supplementary-material.

Chemistry. On the Advantage of Using Well-Defined Catalytic Systems. Dalton Trans. 39, 7595-7606. doi:10.1039/C0DT00218F

Egly, J., Bissessar, D., Achard, T., Heinrich, B., Steffanut, P., Mauro, M., et al. (2021). Copper(I) Complexes with Remotely Functionalized Phosphine Ligands: Synthesis, Structural Variety, Photophysics and Effect onto the Optical Properties. Inorg. Chim. Acta 514, 119971. doi:10.1016/j.ica.2020.119971

Guo, F., Wei, Y.-P., Wang, S.-Q., Zhang, X.-Y., Wang, F.-M., and Sun, W.-Y. (2019). Pt Nanoparticles Embedded in Flowerlike NH2-UiO-68 for Enhanced Photocatalytic Carbon Dioxide Reduction. J. Mater. Chem. A. 7 (46), 26490-26495. doi:10.1039/c9ta10575a

Hardt, H. D., and Pierre, A. (1973). Fluorescence Thermochromism of Pyridine Copper Iodides and Copper Iodide. Z. Anorg. Allg. Chem. 402 (1), 107-112. doi:10.1002/zaac.19734020113

Hassanein, K., Cappuccino, C., Amo-Ochoa, P., López-Molina, J., Maini, L., Bandini, E., et al. (2020). Multifunctional Coordination Polymers Based on Copper(i) and Mercaptonicotinic Ligands: Synthesis, and Structural, Optical and Electrical Characterization. Dalton Trans. 49 (30), 10545-10553. doi:10.1039/d0dt01127d

Hei, X., Fang, Y., Teat, S. J., Farrington, C., Bonite, M., and Li, J. (2021). Copper(I) Iodide-Based Organic-Inorganic Hybrid Compounds as Phosphor Materials. J. Z. für Naturforschung B 76 (10-12), 759-764. doi:10.1515/znb-2021-0126

Hofbeck, T., Niehaus, T. A., Fleck, M., Monkowius, U., and Yersin, H. (2021). PกN Bridged $\mathrm{Cu}(\mathrm{I})$ Dimers Featuring Both TADF and Phosphorescence. From Overview towards Detailed Case Study of the Excited Singlet and Triplet States. Molecules 26 (11), 3415. doi:10.3390/ molecules 26113415

Kaeser, A., Mohankumar, M., Mohanraj, J., Monti, F., Holler, M., Cid, J.-J., et al. (2013). Heteroleptic Copper(I) Complexes Prepared from Phenanthroline and Bis-Phosphine Ligands. Inorg. Chem. 52 (20), 12140-12151. doi:10.1021/ ic4020042

Kutal, C. (1990). Spectroscopic and Photochemical Properties of D10 Metal Complexes. Coord. Chem. Rev. 99, 213-252. doi:10.1016/0010-8545(90) 80064-Z

Liang, X.-Q., Gupta, R. K., Li, Y.-W., Ma, H.-Y., Gao, L.-N., Tung, C.-H., et al. (2020). Structural Diversity of Copper(I) Cluster-Based Coordination Polymers with Pyrazine-2-Thiol Ligand. Inorg. Chem. 59, 2680-2688. doi:10.1021/ acs.inorgchem.9b02919

Liu, W., Fang, Y., and Li, J. (2018). Copper Iodide Based Hybrid Phosphors for Energy-Efficient General Lighting Technologies. Adv. Funct. Mater. 28 (8), 1705593. doi:10.1002/adfm.201705593

Liu, W., Zhu, K., Teat, S. J., Deibert, B. J., Yuan, W., and Li, J. (2017). A Mechanochemical Route toward the Rational, Systematic, and Cost-Effective green Synthesis of Strongly Luminescent Copper Iodide Based Hybrid Phosphors. J. Mater. Chem. C 5 (24), 5962-5969. doi:10.1039/C7TC00889A

Lv, L., Wang, S. Q., and Liu, W. (2021). Copper Iodide Organic-Inorganic Hybrid Chelating Clusters as Luminescent Coating Materials. Inorg. Chim. Acta 518, 120241. doi:10.1016/j.ica.2020.120241

Trose, M., Nahra, F., and Cazin, C. S. J. (2018). Dinuclear N-Heterocyclic Carbene Copper(I) Complexes. Coord. Chem. Rev. 355, 380-403. doi:10.1016/ j.ccr.2017.10.013

Tsuge, K., Chishina, Y., Hashiguchi, H., Sasaki, Y., Kato, M., Ishizaka, S., et al. (2016). Luminescent Copper(I) Complexes with Halogenido-Bridged 
Dimeric Core. Coord. Chem. Rev. 306, 636-651. doi:10.1016/ j.ccr.2015.03.022

Wang, F.-M., Hu, B.-X., Lustig, W. P., Zhou, L., Xiang, J., Chen, L.-Z., et al. (2021). Three Robust Blue-Emitting Anionic Metal-Organic Frameworks with High Stability and Good Proton Conductivities. Inorg. Chem. 60, 17926-17932. doi:10.1021/acs.inorgchem.1c02499

Wang, F.-M., Zhou, L., Lustig, W. P., Hu, Z., Li, J.-F., Hu, B.-X., et al. (2018). Highly Luminescent Metal-Organic Frameworks Based on an Aggregation-Induced Emission Ligand as Chemical Sensors for Nitroaromatic Compounds. Cryst. Growth Des. 18 (9), 5166-5173. doi:10.1021/acs.cgd.8b00604

Wang, F., Liu, W., Teat, S. J., Xu, F., Wang, H., Wang, X., et al. (2016). Chromophore-immobilized Luminescent Metal-Organic Frameworks as Potential Lighting Phosphors and Chemical Sensors. Chem. Commun. 52 (67), 10249-10252. doi:10.1039/c6cc05290h

Wang, Z. P., Yu, S. S., Zhang, H., and Duan, H. B. (2019). Thermochromic Luminescence and Dielectric Response of Copper(I) Iodide Based MOFs as Luminescent Thermometer. Synth. Met., 255, 116104. doi:10.1016/j.synthmet.2019.116104

Xu, C., Li, Y., Lv, L., Lin, F., Lin, F., Zhang, Z., et al. (2020a). Synthesis, Characterization, Luminescence Properties of Copper(I) Bromide Based Coordination Compounds. Inorg. Chim. Acta 512, 119893. doi:10.1016/j.ica.2020.119893

Xu, K., Chen, B.-L., Zhang, R., Liu, L., Zhong, X.-X., Wang, L., et al. (2020b). From a Blue to white to Yellow Emitter: a Hexanuclear Copper Iodide Nanocluster. Dalton Trans. 49 (18), 5859-5868. doi:10.1039/c9dt04701h

Yu, M., Liu, C., Li, S., Zhao, Y., Lv, J., Zhuo, Z., et al. (2020). Constructing MultiCluster Copper(i) Halides Using Conformationally Flexible Ligands. Chem. Commun. 56 (53), 7233-7236. doi:10.1039/d0cc02472d
Zhang, B., Zhang, J., Sun, A., Liu, C., Gu, M., Chen, Y., et al. (2021). Efficiently Luminescent Mononuclear Copper Iodide Complexes with Sterically Hindered Iminephosphine Chelating Ligands. New J. Chem. 45 (19), 8763-8768. doi:10.1039/d1nj00622c

Zhao, Y. F., Yu, M. X., Jiang, F. L., Chen, L., and Hong, M. C. (2021). A RedEmissive 3D Framework with the Coexistence of Copper-Iodide Clusters and Rings as a Luminescent Ratiometric Thermometer. Inorg. Chem. Commun. 127, 108517. doi:10.1016/j.inoche.2021.108517

Conflict of Interest: The authors declare that the research was conducted in the absence of any commercial or financial relationships that could be construed as a potential conflict of interest.

Publisher's Note: All claims expressed in this article are solely those of the authors and do not necessarily represent those of their affiliated organizations, or those of the publisher, the editors and the reviewers. Any product that may be evaluated in this article, or claim that may be made by its manufacturer, is not guaranteed or endorsed by the publisher.

Copyright (C) 2022 Mensah, Shao, Ni, Li, Wang and Chen. This is an open-access article distributed under the terms of the Creative Commons Attribution License (CC $B Y)$. The use, distribution or reproduction in other forums is permitted, provided the original author(s) and the copyright owner(s) are credited and that the original publication in this journal is cited, in accordance with accepted academic practice. No use, distribution or reproduction is permitted which does not comply with these terms. 